\title{
A genetic variant protective against severe COVID-19 is inherited from Neandertals
}

\section{Authors}

Hugo Zeberg ${ }^{1,2^{*}}$ and Svante Pääbo ${ }^{1,3^{*}}$

\author{
Affiliations \\ ${ }^{1}$ Max Planck Institute for Evolutionary Anthropology, Deutscher Platz 6, D-04103 Leipzig, Germany. \\ ${ }^{2}$ Department of Neuroscience, Karolinska Institutet, SE-17177 Stockholm, Sweden. \\ ${ }^{3}$ Okinawa Institute of Science and Technology, Onna-son, Okinawa 904-0495, Japan.
}

*Corresponding authors: hugo.zeberg@ki.se, paabo@eva.mpg.de

\begin{abstract}
It was recently shown that the major genetic risk factor associated with becoming severely ill with COVID-19 when infected by SARS-CoV-2 is inherited from Neandertals. Thanks to new genetic association studies additional risk factors are now being discovered. Using data from a recent genomewide associations from the Genetics of Mortality in Critical Care (GenOMICC) consortium, we show that a haplotype at a region associated with requiring intensive care is inherited from Neandertals. It encodes proteins that activate enzymes that are important during infections with RNA viruses. As compared to the previously described Neandertal risk haplotype, this Neandertal haplotype is protective against severe COVID-19, is of more moderate effect, and is found at substantial frequencies in all regions of the world outside Africa.
\end{abstract}




\section{Main text}

Neandertals and Denisovans are archaic hominin groups that became extinct about 40,000 years ago (Higham et al. 2014). They have a biological impact on human physiology today through genetic contributions to modern human populations that occurred during the last tens of thousands of years of their existence (e.g., Simonti et al. 2016, Dannemann and Kelso 2017). Several of these contributions affect genes involved in the immune system (e.g., Laurent et al. 2011, Quach et al. 2016). In particular, variants at several loci containing genes involved in innate immunity come from Neandertals and Denisovans, for example toll-like receptor gene variants which decrease the susceptibility to Helicobacter pylori infections and increase the risk for allergies (Dannemann et al. 2016).

Recently, it was shown that a region on chromosome 3 harbors the major genetic risk locus for becoming critically ill upon infection with the novel coronavirus SARS-CoV-2 (Ellinghaus et al. 2020) and that the haplotype that confers the risk was contributed by Neandertals to modern humans (Zeberg and Pääbo 2020). This haplotype reaches carrier frequencies of up to $\sim 65 \%$ in South Asia whereas it is almost absent in East Asia and occurs at $\sim 16 \%$ in Europe. Thus, although this haplotype is detrimental for its carriers during the current pandemic, it has likely been beneficial in earlier times in South Asia, perhaps by conferring protection against other pathogens.

A new study from the GenOMICC consortium, which includes 2,244 critically ill COVID-19 patients and controls (Pairo-Castineira et al. 2020), identifies three new loci with genome-wide significant effects in addition to the risk locus on chromosome 3 located on chromosomes 12, 19 and 21. To test if any of these loci carry variants derived from Neandertals, we investigated if alleles of the index variants at these loci co-segregate in the population with alleles of single nucleotide polymorphisms (SNPs) that match three high-quality Neandertals genomes, while being absent in the genomes of 108 African Yoruba individuals $\left(\mathrm{r}^{2}>0.75\right.$ in all genomes of the 1000 Genomes Project). No SNPs fulfilling these criteria were found in two of the novel loci whereas 43 such SNPs exists at the chromosome 12 locus.

To further investigate this locus, we used the round 4 (alpha) release of the COVID-19 Host Genetics Initiative (HGI) (covid19hg.org) to analyze 35 SNPs that are significantly associated with severe COVID19 and have been scored in the archaic genomes (Table S1). A 60,000 to 80,000-year-old Neandertal from Chayrskaya Cave in southern Siberia (Mafessoni et al. 2020) carries the protective alleles at 34 of these SNPs in a homozygous form, while an approximately 50,000-year-old Neandertal from Vindija in Croatia (Prüfer et al. 2017) carries the protective alleles in a homozygous form at 33 SNPs. An approximately 120,000-year-old Neandertal from Denisova Cave in southern Siberia (Prüfer et al. 2014) carries 
protective alleles in homozygous form at 30 of the SNPs and in a heterozygous form at three of the SNPs. In contrast, only two of the protective alleles match the Denisovan genome (Meyer et al. 2012). Thus, for almost all SNPs with genome-wide significance on chromosome 12, the Neandertals carry the allele that decrease the risk of requiring hospitalization upon SARS-CoV-2 infection. In the GenOMICC study, the risk of carriers of the index variant of the haplotype (rs10735079, $\mathrm{p}=1.7 \mathrm{e}-8$ ) of needing intensive care is reduced by $\sim 22 \%$ (under the rare disease assumption, $\mathrm{OR}=0.78,95 \%$ confidence interval $(\mathrm{CI}): 0.71$ $0.85)$.

By identifying sets of Neandertals alleles that co-segregate in humans living today, we find a Neandertallike segment of $\sim 90$ kilobases $(\mathrm{kb})$ (chr12:113,345,168-113,435,449; hg19) which overlaps the genomic region harboring SNPs associated with severe COVID-19 (Fig 1; Methods). Genomic segments with similarity to Neandertal genomes may either derive from common ancestors of the two groups living about half a million years ago or be contributed by Neandertals to modern humans when the two groups met less than 100,000 years ago (Sankararaman et al. 2012). To distinguish these two alternatives, we use the recombination rate of the genomic region $(0.80 \mathrm{cM} / \mathrm{Mb})$ (Kong et al. 2002), a generation time of 29 years (Langergraber et al. 2012), a split between Neandertals and modern humans of 550,000 years (Prüfer et al. 2014), interbreeding between the two groups $\sim 50,000$ years ago, and a published equation (Huerta-Sánchez et al. 2014) to test if a segment of this length may have survived since the common ancestor of the groups without being broken down by recombination that affect chromosomes in each generation. Under these assumptions, we exclude that it derives from the common ancestor $(p=1.1 \mathrm{e}-10)$ and conclude that this region entered the human gene pool from Neandertals. In agreement with this, a previous study (Mendez et al. 2013) has described gene flow from Neandertals in this region. We find that the index allele, i.e. the Neandertal allele with the greatest association with severe COVID-19 (rs4766664), occurs in all populations in Eurasia and Americas at frequencies that often reach and exceed $30 \%$ (Fig. 2).

The Neandertal haplotype protective against severe COVID-19 is located in a region in chromosome 12 that contain the three genes $O A S 1, O A S 2$ and $O A S 3$, all of which encode oligoadenylate synthetases. These enzymes are induced by interferons and activated by double-stranded RNA. They produce shortchain polyadenylates, which in turn activate ribonuclease L, which degrades intracellular RNA, and activate other antiviral mechanisms in infected cells (reviewed by Choi et al. 2015).

To investigate which of these genes might be involved in the protection against severe COVID-19, we plot the genomic location of the $O A S$ genes below the p-values for the association and the introgressed Neandertal haplotype (Fig. 1). The association ( $<<1 \mathrm{e}-6)$ overlaps all three $O A S$ genes. The SNPs with the 
most significant associations ( $\mathrm{p}<5 \mathrm{e}-8)$ are situated in the 3 '-end of $O A S 1$ and in $O A S 3$, and thus these two genes are most likely to be involved in the protective effect(s) of the Neandertal haplotype.

There are several SNPs on the Neandertal haplotype, which stand out as potentially functionally important in this region. One SNP (rs10774671) has been noted to affect a splice acceptor site (Sams et al. 2016). The most common allele at this SNP is derived and alters splicing of the OAS1 transcript that produces an ancestral protein isoform (p46) to several alternative transcripts ( $\mathrm{Li}$ et al. 2017). The ancestral isoform, preserved in Neanderthals, has been shown to have a higher enzymatic activity (Bonnevie-Nielsen et al. 2005). Outside Africa the ancestral allele is only present in individuals with the Neandertal haplotype whereas in Africa it exists independently of this haplotype presumably as a genetic variant inherited from the common ancestors of modern humans and Neandertals that was lost in the modern human population that left Africa (Sams et al. 2016). We note that a previous study (Carey et al. 2019) has identified recurrent $O A S 1$ loss-of-function mutations in primates, suggesting a cost of OAS1 enzymatic activity. In addition to the splice acceptor site, the $90 \mathrm{~kb}$ Neandertal haplotype contains a missense variant (rs2660) in one $O A S 1$ transcript, a missense variant (rs1859330) and two synonymous variants (rs1859329, rs2285932) in $O A S 3$, and a missense variant in OAS2 (rs1293767).

The haplotype on chromosome 12 has previously been studied with respect to its effects on other viral infections. Notably, the Neandertal missense variant in OAS1 (or variants in linkage disequilibrium with this variant) has been shown to be associated with moderate to strong protection against SARS-CoV (rs2660, OR $=0.42,95 \%$ CI: 0.20-0.89) (He et al. 2006), although this study was limited in number of SARS-CoV cases and controls. The Neandertal-like splice acceptor variant has similarly been associated with protection against West Nile Virus (rs10774671, OR =0.63, 95\% CI: 0.5-0.83, Kim et al. 2009) and the Neandertal-like haplotypes have been associated with increased resistance to hepatitis $\mathrm{C}$ infections (El Awady et al. 2011). Furthermore, the Neandertal versions of the $O A S$ genes are expressed differently in response to different viral infections both in terms of expression levels and splice forms (Sams et al. 2016). Thus, it is entirely possible that the $O A S$ locus has been subject to distinct selective pressures by different pathogens during the hundreds of thousands of years that Neandertals and the ancestors of modern humans lived in western Eurasia and Sub-Saharan Africa, respectively.

After these groups came into contact and fused $~ 50,000$ years ago, they became exposed to novel pathogens. Some of the variants contributed by Neandertals rose to high frequencies either locally, as is the case in South Asia for the Neandertal haplotype on chromosome 3 (Zeberg and Pääbo 2020), or almost everywhere in Eurasia, as is the case for the Neandertal haplotype on chromosome 12 (Fig. 2). With almost the entire world population now exposed to the novel SARS-CoV-2, the former haplotypes 
turn out to be detrimental while the latter haplotype turns out to be beneficial. Unfortunately, the protection against severe disease conferred by the Neandertal $O A S$ locus is substantially smaller than the increased risk conferred by the chromosome 3 locus.

\section{Methods}

The index variants for the three novel loci (rs10735079, rs2109069, rs2236757) were obtained from GenOMICC (Pairo-Castineira et al. 2020). The regional summary statistics from the round 4 (alpha) release of the meta-analysis carried out by the COVID-19 Host Genetics Initiative (https://covid19hg.org/ results) was used to analyze the chromosome 12 locus. Linkage disequilibrium was calculated using LDlink 4.1 and alleles were compared to the archaic genomes using tabix (HTSlib 1.10). The Neandertal haplotype covering the region was investigated using sites where the Neandertal allele is not present in 108 Yoruba individuals (1000G Genomes Project), and the distances between the first two SNPs which cause the LD to fall below 0.75 in Europeans was taken as the length of the Neandertal haplotype. The probability of observing a haplotype of a certain length or longer due to incomplete lineage sorting was calculated as described (Huerta-Sánchez et al. 2014). The inferred ancestral states at variable positions among present-day humans were taken from Ensembl. Maps displaying allele frequencies of different populations were made using Mathematica 11.0 (Wolfram Research, Inc., Champaign, IL) and OpenStreetMap data.

Acknowledgments. We are indebted to the COVID-19 Host Genetics Initiative (HGI) for making the GWAS data available and to the Max Planck Society and the NOMIS Foundation for funding. 


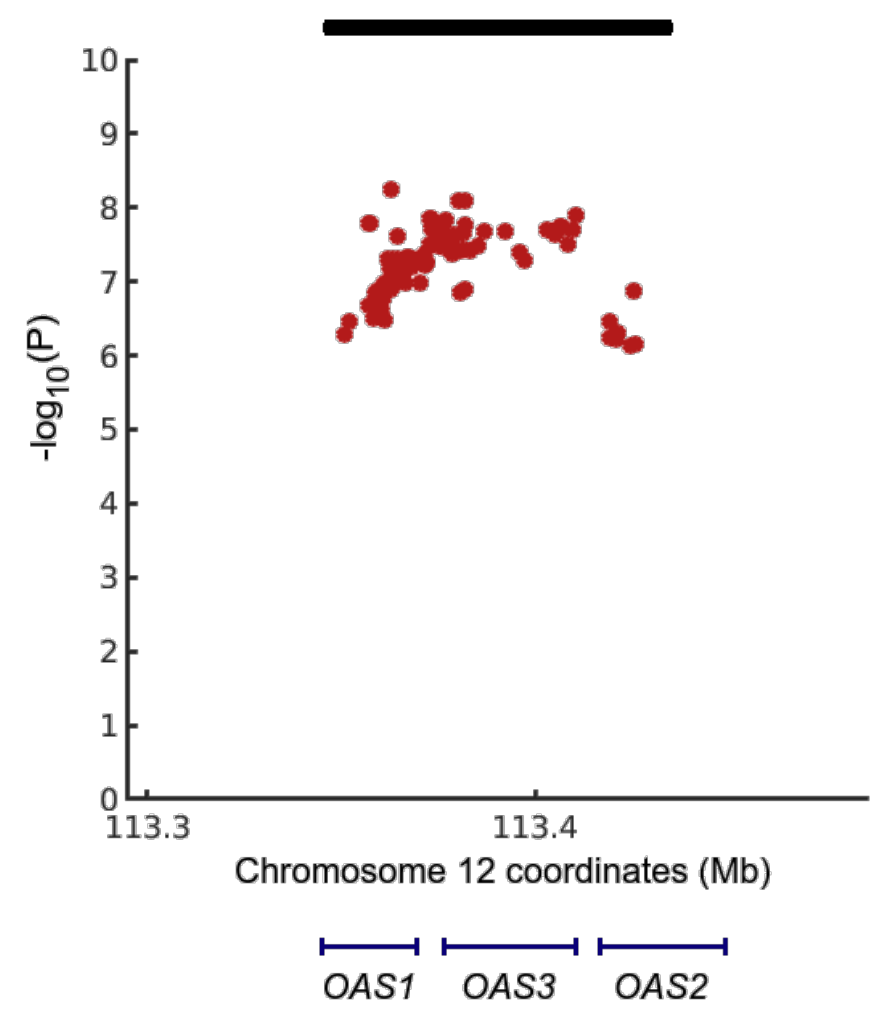

Figure 1. Genetic variants associated with COVID-19 hospitalization $(\mathrm{p}<1 \mathrm{e}-6)$ at the $O A S$ locus.

Black bar indicates a Neanderal haplotype defined by 66 diagnostic Neandertal variants in linkage disequilibrium in Europeans $\left(\mathrm{r}^{2}>0.75\right.$, Methods, Fig. S1). Blue lines indicate the three $O A S$ genes, all of which are transcribed from left to right. The $X$-axis gives $h g 19$ coordinates. 


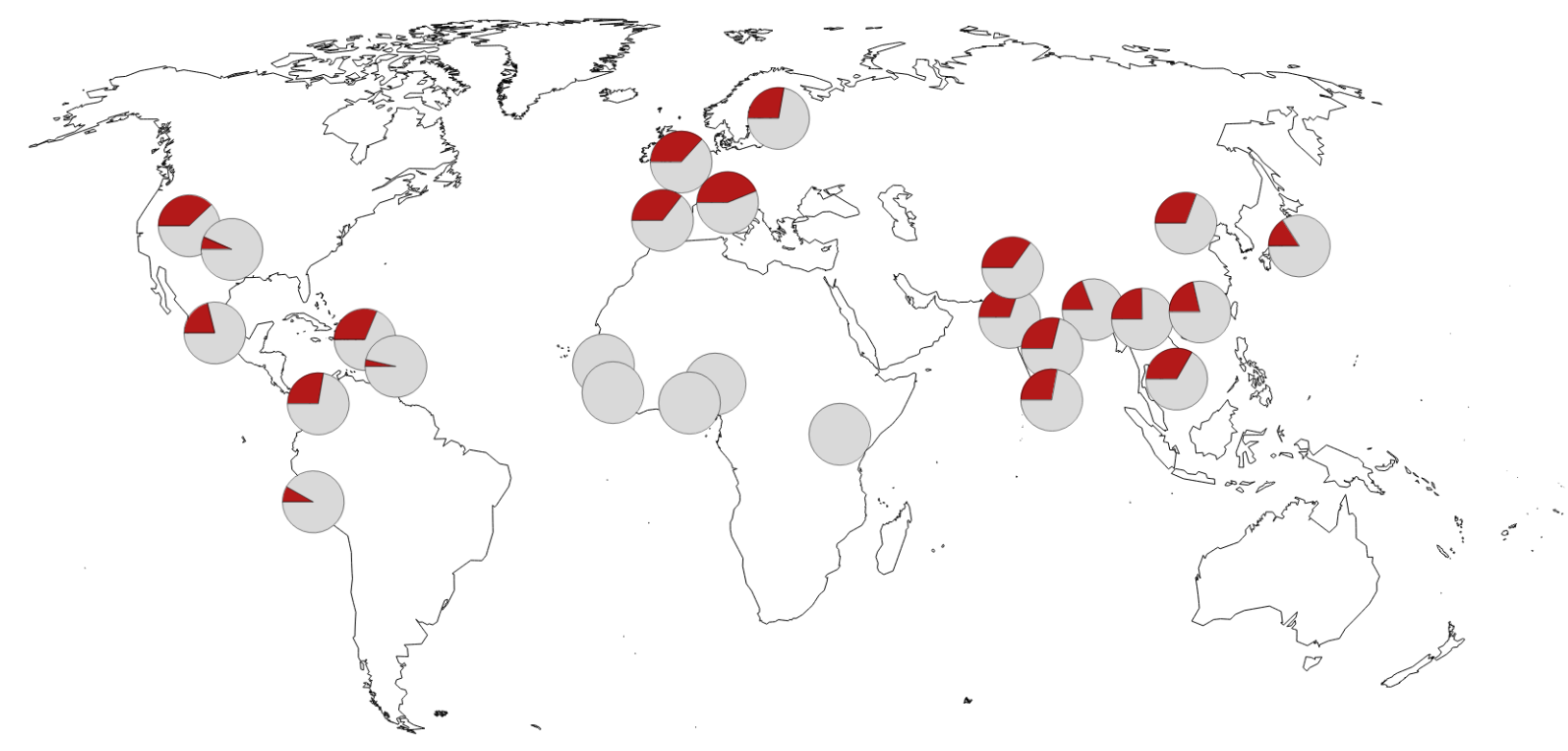

Figure 2. Geographic distribution of the allele indicative of the Neandertal haplotype protective against severe COVID-19. Pie charts indicate minor allele frequency at rs4766664. Frequency data from the 1000 Genomes Project. Map source data from OpenStreetMap. 


\section{References}

1. Bonnevie-Nielsen, V. et al. (2005) Variation in antiviral 2-prime,5-prime-oligoadenylate synthetase (2-prime5-prime AS) enzyme activity is controlled by a single-nucleotide polymorphism at a splice-acceptor site in the OAS1 gene. Am. J. Hum. Genet. doi: $10.1086 / 429391$

2. Carey, C.M. et al. (2019) Recurrent loss-of-function mutations reveal costs to OAS1 antiviral activity in primates. Cell Host Microbe. doi: 10.1016/j.chom.2019.01.001

3. Choi, U.Y. et al. (2015) Oligoadenylate synthase-like (OASL) proteins: dual functions and associations with diseases. Exp. Mol. Med. doi: 10.1038/emm.2014.110

4. Dannemann, M. et al. (2016) Introgression of Neandertal- and Denisovan-like Haplotypes Contributes to Adaptive Variation in Human Toll-like Receptors. Am. J. Hum. Genet. doi: 10.1016/j.ajhg.2015.11.015

5. Dannemann, M. and Kelso, J. (2017) The Contribution of Neanderthals to Phenotypic Variation in Modern Humans. Am. J. Hum. Genet. doi: 10.1016/j.ajhg.2017.09.010

6. El Awady, M.K. et al. (2011) Single nucleotide polymorphism at exon 7 splice acceptor site of OAS1 gene determines response of hepatitis $\mathrm{C}$ virus patients to interferon therapy. $J$. Gastroenterol. Hepatol. doi: 10.1111/j.1440-1746.2010.06605.x

7. Ellinghaus, D. et al. (2020) Genome-wide Association Study of Severe Covid-19 with Respiratory Failure. NEJM. doi: 10.1056/NEJMoa2020283

8. He, J. et al. (2020) Association of SARS susceptibility with single nucleic acid polymorphisms of OAS1 and MxA genes: a case-control study. BMC Infectious Diseases. doi: 10.1186/1471-23346-106

9. Higham, T. et al. (2014) The timing and spatiotemporal patterning of Neanderthal disappearance. Nature. doi: 10.1038/nature13621

10. Huerta-Sánchez, E. et al. (2014) Altitude adaptation in Tibetans caused by introgression of Denisovan-like DNA. Nature. doi: 10.1038/nature13408 
11. Kim, JK. et al. (2009) Genetic Variation in OAS1 Is a Risk Factor for Initial Infection with West Nile Virus in Man. PLOS Pathogens. doi: 10.1371/journal.ppat.1000321

12. Kong, A. et al. (2002). A high-resolution recombination map of the human genome. Nat. Genet. doi: $10.1038 / \mathrm{ng} 917$

13. Langergraber, K.E. et al. (2012) Generation times in wild chimpanzees and gorillas suggest earlier divergence times in great ape and human evolution. Proc. Natl. Acad. Sci. U.S.A. doi: 10.1073/pnas.1211740109

14. Laurent, A. et al. (2011) The Shaping of Modern Human Immune Systems by Multiregional Admixture with Archaic Humans. Science. doi: 10.1126/science.1209202

15. Li, H. et al. (2017) Identification of a Sjögren's syndrome susceptibility locus at OAS1 that influences isoform switching, protein expression, and responsiveness to type I interferons. PLOS Genetics. doi: 10.1371/journal.pgen.1006820

16. Mafessoni, F. et al. A high-coverage Neandertal genome from Chagyrskaya Cave. Proc. Natl. Acad. Sci. U.S.A. doi: 10.1073/pnas.2004944117

17. Meyer, M. et al. (2012) A high-coverage genome sequence from an archaic Denisovan individual. Science. doi: 10.1126/science. 1224344

18. Pairo-Castineira, E. et al. (2020) Genetic mechanisms of critical illness in Covid-19. medRxiv. doi: 10.1101/2020.09.24.20200048

19. Prüfer, K. et al. (2014) The complete genome sequence of a Neanderthal from the Altai Mountains. Nature. doi: 10.1038/nature12886

20. Prüfer, K. et al. (2017) A high-coverage Neandertal genome from Vindija Cave in Croatia. Science. doi: 10.1126/science.aao1887

21. Quach, H. et al. (2016). Genetic adaptation and Neandertal admixture shaped the immune system of human populations. Cell. doi: 10.1016/j.cell.2016.09.02410.1016/j.cell.2016.09.024

22. Sams, A.J. et al. (2016) Adaptively introgressed Neandertal haplotype at the OAS locus functionally impacts innate immune responses in humans. Genome Biol. doi: 10.1186/s13059016-1098-6. 
23. Sankararaman, S. et al. (2012). The date of interbreeding between Neandertals and modern humans. PLoS Genet. doi: 10.1371/journal.pgen.1002947

24. Simonti, C.N. et al. (2016). The phenotypic legacy of admixture between modern humans and Neandertals. Science. doi: 10.1126/science.aad2149

25. Zeberg, H. and Pääbo, S. (2020) The major genetic risk factor for severe COVID-19 is inherited from Neanderthals. Nature. doi: 10.1038/s41586-020-2818-3. 
bioRxiv preprint doi: https://doi.org/10.1101/2020.10.05.327197; this version posted October 9, 2020. The copyright holder for this preprint

(which was not certified by peer review) is the author/funder, who has granted bioRxiv a license to display the preprint in perpetuity. It is made available under aCC-BY 4.0 International license.

\section{Supplementary material}

Table S1. Genome-wide significant variants $(\mathrm{p}<5 \mathrm{e}-8)$ on chromosome 12.

Figure S1. Diagnostic Neandertal variants and their pairwise linkage disequilibrium in Europeans. 
bioRxiv preprint doi: https://doi.org/10.1101/2020.10.05.327197; this version posted October 9, 2020. The copyright holder for this preprint

\begin{tabular}{|c|c|c|c|c|c|c|c|c|c|c|c|}
\hline Chr & Pos & rsid & P-value & LD (rs4766664) & Ref & Alt & Anc & Vindija & Altai & Chagyrskaya & Denisova \\
\hline 12 & 113362997 & rs4766664 & $5.7 e-09$ & 1.00 & $\mathrm{~T}$ & G & $\mathrm{T}$ & $T / T$ & $\mathrm{~T} / \mathrm{T}$ & $\mathrm{T} / \mathrm{T}$ & G/G \\
\hline 12 & 113381956 & rs2269899 & $7.9 \mathrm{e}-09$ & 0.56 & C & $\mathrm{T}$ & $\mathrm{T}$ & $\mathrm{C} / \mathrm{C}$ & $\mathrm{C} / \mathrm{C}$ & $\mathrm{C} / \mathrm{C}$ & $\mathrm{T} / \mathrm{T}$ \\
\hline 12 & 113380008 & rs 10735079 & $7.9 e-09$ & 0.75 & G & A & A & $G / G$ & $G / G$ & G/G & $\mathrm{A} / \mathrm{A}$ \\
\hline 12 & 113410316 & rs 10744791 & $1.3 e-08$ & 0.63 & G & A & A & $G / G$ & $A / G$ & G/G & $\mathrm{A} / \mathrm{A}$ \\
\hline 12 & 113372804 & rs4767037 & $1.4 \mathrm{e}-08$ & 0.98 & A & C & A & $\mathrm{A} / \mathrm{A}$ & $\mathrm{A} / \mathrm{A}$ & $\mathrm{A} / \mathrm{A}$ & $\mathrm{C} / \mathrm{C}$ \\
\hline 12 & 113372866 & rs1981557 & $1.4 \mathrm{e}-08$ & 0.98 & G & C & G & $\mathrm{G} / \mathrm{G}$ & $\mathrm{G} / \mathrm{G}$ & G/G & $\mathrm{C} / \mathrm{C}$ \\
\hline 12 & 113372977 & rs1981555 & $1.4 \mathrm{e}-08$ & 0.98 & $G$ & A & G & . & & . & . \\
\hline 12 & 113376913 & rs7299132 & $1.5 e-08$ & 0.99 & $\mathrm{~T}$ & A & A & $\mathrm{T} / \mathrm{T}$ & $\mathrm{T} / \mathrm{T}$ & $T / T$ & $\mathrm{~A} / \mathrm{A}$ \\
\hline 12 & 113357209 & rs1131476 & $1.6 \mathrm{e}-08$ & 0.92 & G & $A$ & G & $\mathrm{G} / \mathrm{G}$ & $\mathrm{G} / \mathrm{G}$ & $\mathrm{G} / \mathrm{G}$ & $A / A$ \\
\hline 12 & 113357442 & rs2660 & $1.6 e-08$ & 0.92 & G & A & G & $\mathrm{G} / \mathrm{G}$ & $\mathrm{G} / \mathrm{G}$ & $\mathrm{G} / \mathrm{G}$ & $\mathrm{A} / \mathrm{A}$ \\
\hline 12 & 113381695 & rs7131998 & $1.8 \mathrm{e}-08$ & 0.86 & A & C & A & . & . & . & . \\
\hline 12 & 113406196 & rs3937434 & $1.8 \mathrm{e}-08$ & 0.63 & A & $G$ & G & . & . & . & . \\
\hline 12 & 113406460 & rs2016831 & $1.8 \mathrm{e}-08$ & 0.63 & G & C & C & 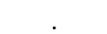 & . & . & . \\
\hline 12 & 113374017 & rs 4767040 & $1.9 \mathrm{e}-08$ & 0.98 & G & C & G & $\mathrm{G} / \mathrm{G}$ & $G / G$ & G/G & $\mathrm{C} / \mathrm{C}$ \\
\hline 12 & 113372961 & rs1981556 & $1.9 \mathrm{e}-08$ & 1.00 & C & G & G & & & & . \\
\hline 12 & 113406945 & rs757405 & $1.9 e-08$ & 0.63 & $\mathrm{~T}$ & A & A & $\mathrm{T} / \mathrm{T}$ & $\mathrm{A} / \mathrm{T}$ & $\mathrm{T} / \mathrm{T}$ & $\mathrm{A} / \mathrm{A}$ \\
\hline 12 & 113373563 & rs3759376 & $1.9 e-08$ & 1.00 & A & $\mathrm{G}$ & G & $\mathrm{A} / \mathrm{A}$ & $\mathrm{A} / \mathrm{A}$ & $\mathrm{A} / \mathrm{A}$ & $\mathrm{G} / \mathrm{G}$ \\
\hline 12 & 113409413 & rs 4767045 & $1.9 \mathrm{e}-08$ & 0.63 & C & $\mathrm{T}$ & $\mathrm{T}$ & $T / T$ & $T / T$ & $\mathrm{C} / \mathrm{C}$ & $\mathrm{T} / \mathrm{T}$ \\
\hline 12 & 113402899 & rs 4767044 & $2.0 \mathrm{e}-08$ & 0.63 & C & A & A & $\mathrm{C} / \mathrm{C}$ & $\mathrm{C} / \mathrm{C}$ & $\mathrm{C} / \mathrm{C}$ & $\mathrm{A} / \mathrm{A}$ \\
\hline 12 & 113373588 & rs3759375 & $2.0 \mathrm{e}-08$ & 1.00 & A & $G$ & G & $\mathrm{A} / \mathrm{A}$ & $\mathrm{A} / \mathrm{A}$ & $\mathrm{A} / \mathrm{A}$ & $G / G$ \\
\hline 12 & 113386950 & rs2285932 & $2.0 e-08$ & 0.63 & $\mathrm{~T}$ & C & $\mathrm{C}$ & $\mathrm{T} / \mathrm{T}$ & $\mathrm{T} / \mathrm{T}$ & $\mathrm{T} / \mathrm{T}$ & $\mathrm{C} / \mathrm{C}$ \\
\hline 12 & 113375036 & rs7132797 & $2.1 \mathrm{e}-08$ & 0.98 & A & C & A & $\mathrm{A} / \mathrm{A}$ & $\mathrm{A} / \mathrm{A}$ & A/A & $\mathrm{C} / \mathrm{C}$ \\
\hline 12 & 113392182 & rs7310667 & $2.1 \mathrm{e}-08$ & 0.31 & A & G & A & & & & . \\
\hline 12 & 113381376 & rs6489882 & $2.2 \mathrm{e}-08$ & 0.97 & G & A & A & $\mathrm{A} / \mathrm{A}$ & $\mathrm{A} / \mathrm{A}$ & $\mathrm{A} / \mathrm{A}$ & $\mathrm{A} / \mathrm{A}$ \\
\hline 12 & 113377822 & rs6489879 & $2.3 e-08$ & 0.99 & $G$ & A & G & $G / G$ & $G / G$ & G/G & $A / A$ \\
\hline 12 & 113379123 & rs7311182 & $2.3 e-08$ & 0.99 & $\mathrm{~T}$ & C & C & & & & . \\
\hline 12 & 113405181 & rs1557866 & $2.4 \mathrm{e}-08$ & 0.63 & A & C & C & $\mathrm{A} / \mathrm{A}$ & $\mathrm{A} / \mathrm{A}$ & $\mathrm{A} / \mathrm{A}$ & $\mathrm{C} / \mathrm{C}$ \\
\hline 12 & 113380271 & rs6489880 & $2.4 \mathrm{e}-08$ & 0.99 & C & $\mathrm{T}$ & $\mathrm{T}$ & & & & \\
\hline 12 & 113364382 & rs4767033 & $2.4 \mathrm{e}-08$ & 1.00 & $\begin{array}{l}\mathrm{T} \\
\mathrm{C}\end{array}$ & A & A & $\mathrm{T} / \mathrm{T}$ & $\mathrm{T} / \mathrm{T}$ & $\mathrm{T} / \mathrm{T}$ & $A / A$ \\
\hline 12 & 113378081 & rs4238033 & $2.4 \mathrm{e}-08$ & 0.99 & $\mathrm{~T}$ & A & A & $\mathrm{T} / \mathrm{T}$ & $\mathrm{T} / \mathrm{T}$ & $\mathrm{T} / \mathrm{T}$ & $A / A$ \\
\hline 12 & 113375983 & rs1156361 & $2.6 e-08$ & 1.00 & $\mathrm{~T}$ & $\mathrm{C}$ & $\mathrm{C}$ & $\mathrm{T} / \mathrm{T}$ & $\mathrm{T} / \mathrm{T}$ & $\mathrm{T} / \mathrm{T}$ & $\mathrm{C} / \mathrm{C}$ \\
\hline 12 & 113372539 & rs7966314 & $3.1 e-08$ & 0.98 & A & $G$ & A & $\mathrm{A} / \mathrm{A}$ & $\mathrm{A} / \mathrm{A}$ & $\mathrm{A} / \mathrm{A}$ & $G / G$ \\
\hline 12 & 113408208 & rs2010604 & $3.2 \mathrm{e}-08$ & 0.52 & G & C & C & $G / G$ & $G / G$ & $G / G$ & $G / G$ \\
\hline 12 & 113374748 & rs 10774679 & $3.3 e-08$ & 0.44 & C & $\mathrm{T}$ & C & $\mathrm{C} / \mathrm{C}$ & $\mathrm{C} / \mathrm{C}$ & $\mathrm{C} / \mathrm{C}$ & $\mathrm{C} / \mathrm{C}$ \\
\hline 12 & 113385000 & rs 10850103 & 3.3e-08 & 0.63 & A & $\mathrm{T}$ & $\mathrm{T}$ & $\mathrm{A} / \mathrm{A}$ & $\mathrm{T} / \mathrm{A}$ & $\mathrm{A} / \mathrm{A}$ & $\mathrm{T} / \mathrm{T}$ \\
\hline 12 & 113376320 & rs3815178 & $3.3 e-08$ & 0.99 & C & $\mathrm{T}$ & C & $\mathrm{C} / \mathrm{C}$ & $\mathrm{C} / \mathrm{C}$ & $\mathrm{C} / \mathrm{C}$ & $T / T$ \\
\hline 12 & 113376388 & rs1859330 & $3.4 \mathrm{e}-08$ & 0.53 & G & A & G & $\mathrm{G} / \mathrm{G}$ & $\mathrm{G} / \mathrm{G}$ & $\mathrm{G} / \mathrm{G}$ & $A / A$ \\
\hline 12 & 113381217 & rs6489881 & $3.6 e-08$ & 0.75 & A & $\mathrm{T}$ & A & $\mathrm{A} / \mathrm{A}$ & $\mathrm{A} / \mathrm{A}$ & $\mathrm{A} / \mathrm{A}$ & $\mathrm{T} / \mathrm{T}$ \\
\hline 12 & 113380708 & rs7977345 & $3.7 e-08$ & 0.75 & $A$ & $\mathrm{~T}$ & $\mathrm{~T}$ & $\mathrm{~A} / \mathrm{A}$ & $\mathrm{A} / \mathrm{A}$ & $\mathrm{A} / \mathrm{A}$ & $\mathrm{T} / \mathrm{T}$ \\
\hline 12 & 113379039 & rs7955267 & $3.7 \mathrm{e}-08$ & 0.75 & C & $\mathrm{T}$ & C & . & . & . & . \\
\hline 12 & 113382977 & rs2384074 & $3.7 e-08$ & 0.66 & C & $\mathrm{T}$ & C & . & . & . & . \\
\hline 12 & 113396010 & rs10744789 & $4.1 \mathrm{e}-08$ & 0.35 & $\mathrm{~T}$ & C & C & . & . & . & . \\
\hline 12 & 113371646 & rs9971885 & $4.2 \mathrm{e}-08$ & 1.00 & A & C & C & . & . & . & . \\
\hline 12 & 113378677 & rs4767041 & $4.3 e-08$ & 0.75 & G & A & G & & & & \\
\hline 12 & 113367422 & rs2384072 & $4.6 \mathrm{e}-08$ & 1.00 & $\mathrm{~T}$ & C & $\mathrm{T}$ & $T / T$ & $\mathrm{~T} / \mathrm{T}$ & $T / T$ & $\mathrm{C} / \mathrm{C}$ \\
\hline 12 & 113366899 & rs7306205 & $4.6 e-08$ & 1.00 & $A$ & $G$ & A & $\mathrm{A} / \mathrm{A}$ & $\mathrm{A} / \mathrm{A}$ & $\mathrm{A} / \mathrm{A}$ & $G / G$ \\
\hline 12 & 113367309 & rs1859336 & $4.7 e-08$ & 1.00 & C & $\mathrm{T}$ & C & $\mathrm{C} / \mathrm{C}$ & $\mathrm{C} / \mathrm{C}$ & $\mathrm{C} / \mathrm{C}$ & $\mathrm{T} / \mathrm{T}$ \\
\hline 12 & 113364633 & rs4766667 & $4.8 \mathrm{e}-08$ & 1.00 & G & A & G & & & & \\
\hline 12 & 113370966 & rs1859333 & $4.9 \mathrm{e}-08$ & 1.00 & $\mathrm{~T}$ & C & C & $T / T$ & $T / T$ & $T / T$ & $\mathrm{C} / \mathrm{C}$ \\
\hline 12 & 113368079 & rs6489877 & $4.9 e-08$ & 0.99 & $A$ & $G$ & A & . & . & . & . \\
\hline 12 & 113363408 & rs6489866 & $4.9 e-08$ & 1.00 & A & $\mathrm{G}$ & A & . & . & . & . \\
\hline
\end{tabular}

Table S1. Genome-wide significant variants $(p<5 e-8)$ on chromosome 12. Red marks the minor allele which in all cases shown is protective. Note that the human reference genome carries the Neandertal haplotype. 'Ref', 'Alt', and 'Anc' refer to the reference, alternative and ancestral allele, respectively. LD denotes linkage disequilibrium in the 1000 Genomes Project dataset $\left(\mathrm{r}^{2}\right)$. 

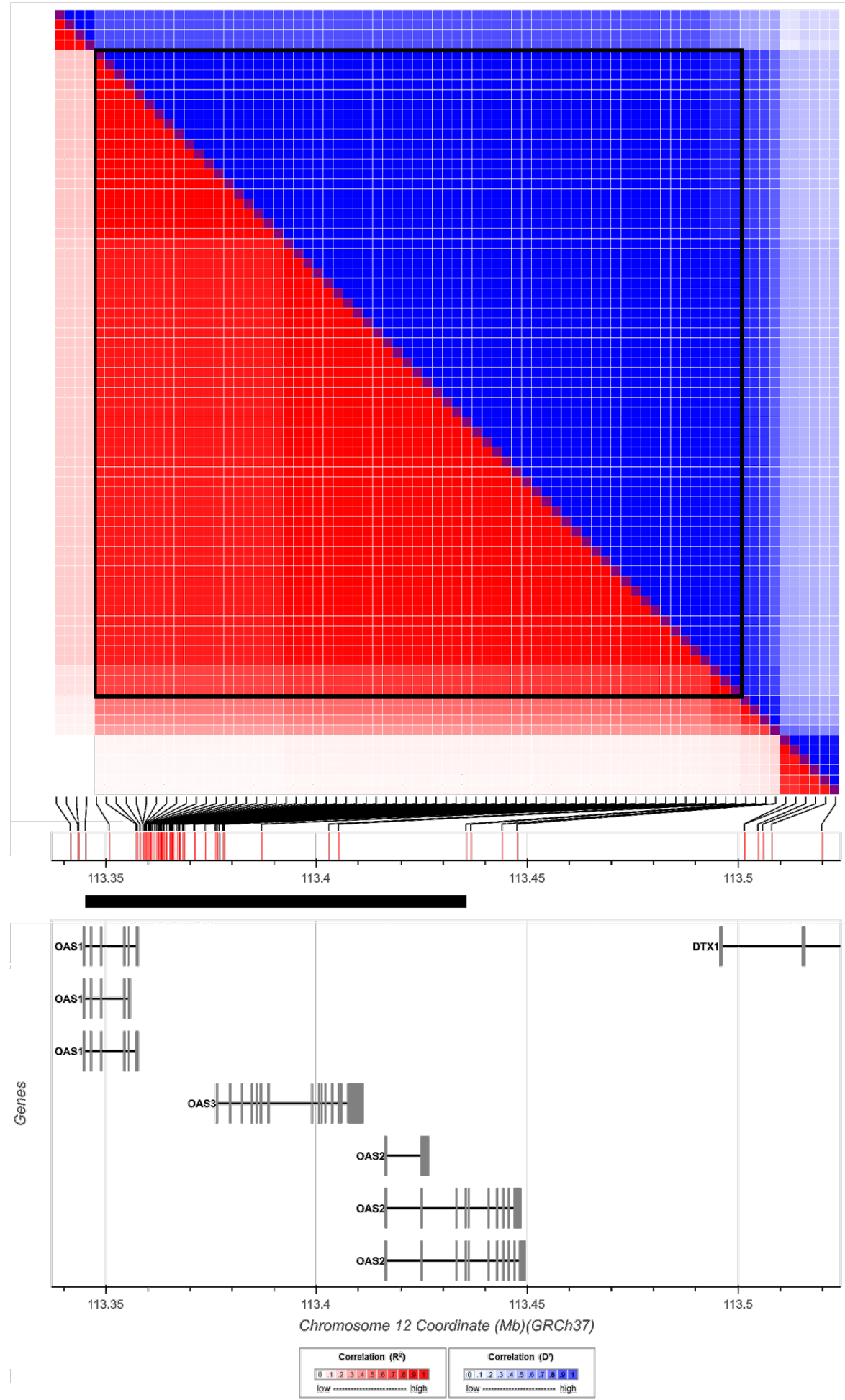

Figure S1. Diagnostic Neandertal variants and their pairwise linkage disequilibrium in Europeans.

Black box indicates a set of 66 diagnostic variants in linkage disequilibrium $\left(\mathrm{r}^{2}>0.75\right)$ defining a haplotype (black bar) with coordinates chr12:113,345,168-113,435,449 (hg19). 

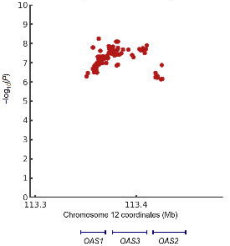
